\title{
Trabajo docente y pandemia. Un análisis socioantropológico de experiencias magisteriales (Rosario, Argentina)
}

Fecha de recepción: 3 de junio de 2020.

Fecha de aceptación: 18 de junio de 2020.

\begin{abstract}
Resumen
En el presente artículo exploramos las experiencias magisteriales que se generan en la actual coyuntura de pandemia con motivo del COVID-19, como parte de los avances de la tesis doctoral. Sostenemos que las pretensiones de trasladar la "escuela al hogar" suponen desafíos y limitaciones y, también, que los procesos de escolarización desplegados en este tiempo de pandemia reconfiguran significativamente el trabajo docente. En el marco de emergencia sanitaria, a partir del 20 de marzo se han interrumpido las clases presenciales en la totalidad de las escuelas argentinas. Los Ministerios de Educación nacional y provinciales han propuesto diversas iniciativas para sostener la escolarización, desde programas radiales y televisivos hasta la distribución de cuadernillos en formato papel. Ahora bien, ¿qué particularidades adquieren dichas estrategias en contextos atravesados por la desigualdad social y la pobreza urbana? ¿De qué modos se reconfigura el trabajo docente? ¿Qué sentidos y prácticas construyen los/ as maestros/as en la actual coyuntura? Un conjunto de interrogantes que, desde un enfoque socioantropológico, orientan la documentación de experiencias de docentes que se desempeñan en escuelas primarias públicas insertas en contextos de pobreza de la ciudad de Rosario.
\end{abstract}

Palabras clave: trabajo docente; experiencias; pandemia; pobreza urbana.

\section{Teaching work and pandemic. A socioanthropological analysis of magisterial experiences (Rosario, Argentina)}

\begin{abstract}
In this article we explore the magisterial experiences that are generated in the current pandemic for the COVID-19, as part of the advances from de doctoral thesis. We support that the claims to move the "school to home" takes challenges and limitations
\end{abstract}


and, also, that the deployed schooling processes in this context of social, prevent and obligatory isolation reconfigure teaching work significantly. In the context of the health emergency, since march 20, the presential classes have been interrupted in argentinian schools. The education ministry, national and provincial, has proposed different initiatives to support schooling, from radial and television programs to the distribution of paper booklets. Now well, what particularities have these strategies in contexts crossed by the social inequality and urban poverty? How the teaching work is reconfigured? What senses and practices do teachers build in this current situation? Many questions that, from a socioanthropological approach, guide the documentation of teachers experiences who perform in Rosario public elementary schools.

Keywords: teaching work; experiences; pandemic; urban poverty.

\section{Introducción}

El año 2020 ha comenzado, casi de modo simultáneo, con la expansión de un virus a nivel global que repercute en la cotidianeidad de millones de personas. Las políticas adoptadas en cada país con motivo del COVID-19 - en materia de salud, economía, educación-configuran un escenario mundial donde confluyen múltiples estrategias. Para el caso de la Argentina, y en el marco de la declaración de la pandemia emitida por la Organización Mundial de la Salud (OMS), desde el 20 de marzo rige el aislamiento social, preventivo y obligatorio (Decreto 297/2020) motivo por el cual se han interrumpido las clases presenciales en la totalidad de las escuelas argentinas. En otras palabras, no asistir a la escuela en la actualidad forma parte de los cuidados que el Estado ha establecido como esenciales para evitar la propagación del virus (Terigi, 2020). Tal disrupción de la cotidianeidad escolar, a pocos días de iniciado el año lectivo, implicó la construcción de alternativas sobre el propio devenir a la vez que reactualizó viejos debates (crisis de la escuela, virtualización de la enseñanza como "la educación del futuro"). Desde los Ministerios de Educación nacional y provinciales se han propuesto diversas estrategias para sostener la escolarización y llegar a todos/as los/as niños/as del país, desde programas educativos que se emiten por televisión y radio, a la elaboración y distribución de cuadernillos en formato papel. Simultáneamente, directivos y docentes han optado por combinarlo con determinados soportes virtuales: plataformas web, classroom, correo electrónico, WhatsApp, Zoom, entre los más recurrentes. Ahora bien, ¿qué particularidades adquieren dichas estrategias en contextos atravesados por la desigualdad social y la pobreza urbana? ¿De qué modos se reconfigura el trabajo docente, tanto en lo referente a los contenidos como en lo vinculado a la relación con los/as niños/as? ¿Qué sentidos y prácticas construyen los/as docentes en la actual coyuntura? Un conjunto de interrogantes desde los cuales documentamos las experiencias de docentes que se desempeñan en escuelas públicas insertas en contextos de pobreza de la ciudad de Rosario.

El enfoque teórico metodológico que orienta la investigación en curso, ${ }^{1}$ de la cual se desprende este escrito, parte de una perspectiva socioantropológica que busca conocer la cotidianeidad escolar como campo en que se entraman distintas dimensiones en sus interdependencias y relaciones históricas contextuales (Achilli, 2005). Consideramos que el trabajo docente se constituye a partir de la combinación de una multiplicidad de prácticas y relaciones institucionales y estructurales históricas, como también por

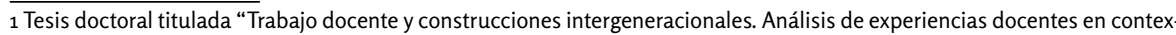
tos de pobreza urbana (Rosario; Argentina)". Directora: Dra. Elena Achilli; codirectora: Dra. María Rosa Neufeld. Doctorado de la Universidad de Buenos Aires (área Antropología), Facultad de Filosofía y Letras. Contó con el apoyo de una beca del Consejo Nacional de investigaciones Científicas y Técnicas (Conicet). 
las significaciones y sentidos que esos condicionantes adquieren socialmente y en los sujetos (Achilli, 1996). Una compleja trama que traspasa la especificidad del trabajo pedagógico (Rockwell, 2013) centrada en esa tríada relacional configurada por el quehacer docente, los conocimientos y los estudiantes alrededor de los procesos de enseñar y aprender (Achilli, 1996).

Metodológicamente, desde 2016 venimos realizando trabajo de campo etnográfico intensivo y en profundidad con maestros/as que se desempeñan en escuelas primarias públicas de distintos barrios de la ciudad de Rosario. El recorte empírico deriva de un mapeo de escuelas insertas en contextos de pobreza atravesados por procesos de desigualdad, en su mayoría, privados de los servicios públicos básicos (desagüe cloacal, agua corriente, luz, transporte público, recolección de residuos). A partir de ello, hemos seleccionado aquellas escuelas con mayor condensación de conflictos según el imaginario social, así como docentes con largas trayectorias en los establecimientos a fin de acceder a prácticas historizadas. Desde entonces, hemos desplegado diversas estrategias investigativas: entrevistas en profundidad a docentes; observación de los procesos escolares, dentro y fuera del aula; como también un proceso de coinvestigación denominado Taller de Educadores (Batallán, 1983; Achilli, 1986; Vera, 1988).

Como anticipación hipotética general, partimos del supuesto de que el trabajo docente en estos contextos urbanos condensa un conjunto de condiciones que le imprimen características y tensiones particulares (Achilli, 1986). A diario, los/as maestros/as articulan una heterogeneidad de situaciones que permea los cotidianos escolares, desde las realidades emergentes de los/as niños/as y adolescentes que concurren a las escuelas; las planificaciones pedagógicas; las solicitudes burocráticas y administrativas; hasta las demandas de las familias, de otras instituciones barriales y de la sociedad en general (Achilli, Pavesio y Vera, 2019). A su vez, planteamos una reconfiguración del trabajo docente en este tiempo de pandemia. Un entramado de condiciones y escenarios contextuales calan en la dinámica actual de su trabajo: jornadas laborales sin días ni horarios fijos, en sus hogares, disponiendo de sus propios recursos tecnológicos y conectividad; familias en condiciones materiales y tecnológicas desiguales; dificultades a la hora de establecer vínculos con los/ as alumnos/as y lograr alguna continuidad pedagógica.

En esta oportunidad, daremos cuenta de determinados procesos que reconfiguran el trabajo docente en contextos de pobreza urbana analizando el material empírico derivado del proceso de documentación que venimos realizando desde la interrupción de las clases presenciales. Haremos referencia, fundamentalmente, a las experiencias que se despliegan en dos escuelas primarias de Rosario a las que, por cuestiones de anonimato, denominaremos A y B. Para ello, describiremos las particularidades que adquiere la educación a distancia en contextos atravesados por la pobreza urbana. Posteriormente, indagaremos los modos en los que se reconfigura el trabajo docente en la actual coyuntura de pandemia tomando en consideración determinados ejes como la relación docente-alumnos/as; la emergencia de nuevos (y reactualización de viejos) soportes y materialidades pedagógicas; las condiciones laborales docentes; el trabajo con los contenidos. Por último, documentaremos determinadas estrategias docentes orientadas a la construcción de vínculos, de nuevas formas de estar y que despliegan aquello que Southwell y Batthjany (2020) denominan imaginación pedagógica.

\section{Hacer escuela... ¿en casa? De límites y potencialidades}

En la tentativa de desarmar el interrogante precedente, proponemos comenzar problematizando qué entendemos por hacer escuela. Siguiendo lo que plantea Dussel (2020a), las escuelas se caracterizan por configurarse como un espacio-tiempo otro, diferente 
del ámbito doméstico o familiar. En ese sentido, Masschelen y Simons (2014) sostienen que las escuelas producen un tiempo en el que las necesidades y las rutinas cotidianas de los/as niños/as pueden dejarse a un lado, suspenderse.

(...) la escuela surge como una concreta materialización y espacialización del tiempo que literalmente separa o saca a los alumnos del (desigual) orden social y económico (el orden de la familia, pero también el orden de la sociedad en su conjunto) y los lleva al lujo de un tiempo igualitario. (Masschelen y Simons, 2014: 12)

Los autores entienden que el acto más importante que hace escuela tiene que ver con la suspensión del orden cotidiano para ofrecer tiempo libre (función democratizadora e igualitaria). Proponen la categoría de suspensión en el sentido de que la escuela torna algo temporalmente inoperante, lo saca de su contexto, ofreciendo la posibilidad de separarse del tiempo y del espacio del hogar (Masschelen y Simons, 2014). La escuela posee el potencial de desactivar, temporalmente, el tiempo ordinario y establecer otras jerarquías, otras dinámicas, otra coreografía de los cuerpos (Dussel, 2020a). Dicha argumentación de la escuela en tanto suspensión del orden cotidiano nos permite tensionar, entonces, la posibilidad de trasladar "la escuela al hogar" ya que se trata de espacios diferenciados, cada uno con sus lógicas y tiempos.

Recordemos que apenas estaba comenzando el ciclo lectivo cuando las clases presenciales debieron interrumpirse. Directivos y docentes comenzaron a ensayar múltiples estrategias para lograr alguna continuidad en los procesos de enseñanza y aprendizaje. En el mejor de los escenarios, una vez contactadas las familias, se establecieron nuevos cronogramas y horarios para las clases virtuales y se continuó con los contenidos pautados a través de plataformas en línea. Pero, ¿qué supone la interrupción de las clases presenciales para "hacer escuela en casa"? Tal pretensión implica una superposición de espacios donde el hogar deviene multifunción y la escuela, en tanto espacio-tiempo otro centrado en el trabajo con el conocimiento, tiende a diluirse o reducirse a la realización de tareas. A este proceso de desdibujamiento de las fronteras entre lo doméstico y lo escolar Dussel (2020a) lo denomina domestización del espacio escolar.

Ahora bien, como nuestro interés se centra en los procesos que ocurren a escala de lo cotidiano, a la pregunta inicial acerca de la posibilidad de hacer escuela en casa podríamos añadir ¿cuál escuela?, ¿dónde? Retomando aquello planteado al comienzo del artículo, nos interrogamos aquí sobre las particularidades que adquiere tal proceso de suspensión de la enseñanza presencial para dar lugar a modalidades a distancia en contextos atravesados por la desigualdad social y la pobreza urbana de la ciudad de Rosario.

\section{La pandemia y sus efectos. Particularidades de la educación a distancia en contextos de pobreza urbana}

Como primera evidencia la pandemia vino a dar mayor visibilidad, sino a profundizar, las desigualdades existentes. En esta oportunidad, centraremos nuestro análisis en torno a dos barrios de la ciudad de Rosario y, especialmente, a dos escuelas ubicadas allí (a las que denominaremos A y B). ${ }^{2}$ En ambos casos, se trata de conglomerados de viviendas emplazadas de forma irregular, muy pocas hechas de ladrillos o material de construcción. Predominan las calles sin asfaltar, con escasos espacios para el

2 Los barrios a los que haremos referencia se encuentran ubicados en la zona oeste de la ciudad de Rosario, ambos en contextos de pobreza urbana. 
esparcimiento, como plazas o clubes. De contar con algunos espacios verdes, estos carecen de mantenimiento o luminaria adecuados. Por otra parte, se trata de dos barrios en donde no están garantizados los servicios básicos, algunas zonas no cuentan con agua corriente, luz, recolección diaria de residuos, transporte público. Un alto porcentaje de sus habitantes posee trabajos informales, están precarizados o vive de "changas", condiciones que se agravan en este contexto donde el imperativo responde a la premisa quedate en casa.

La condición socioeconómica de nuestros alumnos y alumnas es de escasos recursos, están en una situación de vulnerabilidad bastante grande, partiendo de la falta de agua en sus hogares, falta de condiciones indispensables para este momento que estamos atravesando (maestro de $4^{\circ}$ grado, escuela B, registro 23-05-2020).

En el barrio viven familias con escasos recursos económicos, derechos vulnerados y que viven de changas o cirujeo (maestra de $4^{\circ}$ grado, escuela B, registro 26-05-2020).

La están pasando mal, la están pasando complicado, las familias están sin trabajar. El 95\% hacía changas (maestra de $7^{\circ}$ grado, escuela A, registro 22-05-2020).

Ambos barrios cuentan con una escuela de nivel primario donde funciona, también, un comedor escolar. Una de ellas dispone de cocina propia para las raciones diarias de sus alumnos/as (escuela A). En la otra (escuela B), solo se prepara la copa de leche (desayuno y merienda), en tanto la comida es enviada desde otro establecimiento (escuela proveedora). A estas distinciones en cuanto al funcionamiento de la cocina se suman algunas otras. Si bien las circulares emitidas por el Ministerio de Educación de la provincia de Santa Fe, a partir de la situación de emergencia sanitaria, establecían los mismos protocolos para todas las escuelas, en cada una de ellas adquirió sus particularidades.

La escuela B, que recibe la comida de la escuela proveedora, posee una matrícula de ochocientos niños/as. Normalmente, almuerzan allí los/as alumnos/as de los turnos mañana y tarde. Comenzada la pandemia, se estableció el cierre del comedor escolar para dar lugar a la entrega de viandas. Una vez que llegaban los contenedores con mercadería a la escuela, aproximadamente a las $10 \mathrm{am}$, las asistentes escolares la organizaban en viandas para ser retiradas por las familias una hora más tarde. Entre las dificultades con que se encontró la escuela ante esta modalidad se puede citar, por un lado, que no había personal suficiente para el armado de las ochocientas bandejas individuales y, por el otro, que implicaba la circulación diaria de cientos de personas problematizando el cumplimiento del distanciamiento social. Al mismo tiempo, las viandas no representaban porciones significativas. Por tales motivos, desde la escuela se adoptó la modalidad del bolsón de alimentos semanal establecido por el Ministerio de Educación de la provincia de Santa Fe mediante la circular No $8 .{ }^{4}$ Esta mercadería ya no era enviada desde la escuela proveedora sino desde una cocina centralizada ubicada en una localidad cercana a Rosario. El bolsón de alimentos, si bien tiene algunas pequeñas variaciones en cada entrega, carece de carne, frutas y verduras, y contiene de 7 a 8 productos: leche o aceite (se intercalan), harina, polenta, arroz, tomate en lata, arveja en lata, azúcar y yerba.

3 Es una actividad esporádica que por medio de la venta de productos o servicios permite obtener ingresos mínimos (https:// www.diccionarioargentino.com/term/changa).

4 Al principio, el Ministerio estableció que fuese una vez por semana: fideos guiseros ( $500 \mathrm{~g}$ ), arroz (50o g), harina de maíz (500 g), puré de tomate ( $520 \mathrm{~g}), 2$ latas de primavera (320 g cada una), 1 lata de choclo (300 g), harina leudante (1 kg), lentejas (50o g), chocolate/cacao ( $180 \mathrm{~g}$ ). Luego, se entregó cada quince días (con dieciocho productos). De todas maneras, la escuela proveedora le sigue haciendo los envíos a esta escuela cada semana, aunque otras lo reciben cada quince días. 
La situación de la escuela A es diferente. Allí la matrícula es menor, ya que cuenta con doscientos cuarenta alumnos/as. Por un breve período de tiempo, posterior a la pandemia, se continuó con el reparto de la vianda diaria. Luego, por disposición ministerial, se cerró el comedor escolar para sustituirlo por el bolsón de alimentos semanal. Con esta modalidad sucedía que, al ser uno por familia, solo se entregaban ochenta bolsones de alimentos en total, independientemente de la cantidad de niños/ as en edad escolar que asistía al comedor. Por tales motivos, la comunidad decidió elaborar una carta abierta y difundirla en los medios de comunicación para exigir la reapertura del comedor y que se garantizara la ración diaria. ${ }^{5}$ Finalmente, se logró reanudar la preparación de las viandas para los doscientos cuarenta chicos/as. En un primer momento, se estableció el reparto de viandas tres veces por semana y la entrega de un bolsón de alimentos semanal. Luego, esta modalidad se modificó nuevamente para efectuar la entrega de las viandas todos los días de la semana. Este caso representa el único en la provincia ya que las demás escuelas operan mediante la modalidad de entrega de bolsones semanales o quincenales.

Esta breve descripción respecto al funcionamiento del comedor escolar en ambas escuelas resulta relevante para ilustrar cómo la escuela no solo garantiza el derecho a la educación sino otros como, por ejemplo, el de la alimentación. La escuela, en este contexto de suspensión de las clases presenciales y mediante la entrega de alimentos, se transforma no solo en el nexo esencial sino en el único canal de comunicación entre docentes y familias. Así lo expresa una maestra:

Tengo la suerte, porque lo decidí, de ir a la escuela una vez por semana a ayudar con la entrega de bolsones (...) es la forma de estar un poco más en contacto con las familias con las que de otra manera no me puedo comunicar. Lo único positivo de esto, es poder conocer personalmente a esas madres o padres y las realidades que atraviesan (maestra de $4^{\circ}$ grado, escuela $\mathrm{B}$, registro 26-05-2020).

Aquellos/as maestros/as que, de manera voluntaria, asisten a la escuela para colaborar con la entrega de los bolsones consideran que es uno de los modos más efectivos para conocer personalmente a los padres y/o madres, así como sus realidades cotidianas. Aprovechan la ocasión para acercarse a las familias, consultarles cómo están los/as niños/as y saber si están pudiendo realizar las actividades que envían. De todas maneras, entienden que la situación económica y laboral de la mayoría, profundizada por la pandemia, es delicada, resultándoles por momentos hasta contradictorio insistir con las tareas cuando se trata de hogares que no tienen garantizado el sustento diario.

Familias que muchas no están alfabetizadas, o no comprenden las consignas y no se animan a decirlo, o que están pensando cómo conseguir un plato de comida (maestra de $4^{\circ}$ grado, escuela $B$, registro 26-05-2020).

Del registro precedente nos interrogamos sobre las posibilidades concretas que tienen las familias de acompañar los procesos escolares de sus niños/as y si, en ocasiones, el imperativo "hacer escuela en casa" no conlleva implícitamente una concepción romántica del hogar donde se da por supuesto que hay ciertas condiciones dadas como, por ejemplo, la presencia de adultos dispuestos a acompañar, armonía, tranquilidad (Southwell y Batthyany, 2020). Ciertamente, relevamos que la situación es de mayor complejidad. ¿Cuáles son las condiciones objetivas, situadas, de estas familias? En lo referente a las viviendas, un gran porcentaje no cuenta con condiciones habitacionales adecuadas para el trabajo en casa: espacios reducidos que son compartidos por varias personas, insuficiente ventilación, falta de luz y/o agua, conectividad reducida. 
A continuación, presentamos tres registros etnográficos, pertenecientes a una madre, su hijo y la docente, que dan cuenta del escenario contextual anteriormente descripto y de las dificultades que supone "hacer escuela en casa". El primero corresponde a la madre, allí refiere una situación concreta: en su vivienda no tienen luz hace varios días, lo que suscita complicaciones de diverso orden, tanto en lo relacionado a las tareas escolares de su hijo como a los cuidados que debe dispensarle a una de sus hijas recientemente operada:

(...) desde el viernes estamos sin luz. Y hoy ya salimos a hacer cortar la calle y bueno, desde ayer, así que todo el día afuera, vamos y venimos, vamos y venimos y es agotador... menos que teníamos que estar en aislamiento, ahora porque tenemos que andar por el tema de la luz. Hoy a 'J', se me re pasó, no la curé, y ahora en plena oscuridad con vela estoy tratando de curarle la herida... así que es todo un tema, encima que acá, mi casa no tiene muchas ventanas, tiene una sola ventana y es medio oscuro adentro, sí o sí necesito luz para que haga la tarea, si estaría yo de ultima salimos ahí al patio hacemos con carpetas y no pasa nada, pero como no estoy, así que es lo mismo (...) ni bien consigamos el tema de la luz, solucionamos eso, ahí lo pongo de cabeza que se ponga a estudiar, sabe? (mamá de alumno de escuela A, registro 28-05-2020).

Resulta interesante cómo el mismo suceso es percibido por el niño:

(...) no voy a poder hacer tarea porque acá en mi casa no tengo luz, no... y tampoco no puedo buscar cosas por el teléfono, casi nada... Y a la mañana... se ponen a hacer piquete allá (...) y yo tengo que ir, todo también... así que no... estos días no voy a estar pudiendo hacer las tareas... Así que capaz la semana que viene, capaz que nos pongan la luz, todo. Y ahora mañana capaz que, si tengo, si no hacen nada, voy a poder hacer un poco de tarea. Le quería avisar nada más (alumno de escuela A, registro 28-05-2020).

Del ultimo registro se desprenden algunos indicios. Por un lado, cierto interés por parte del niño en las cuestiones escolares, así como una preocupación por no poder "estar al día" con las tareas solicitadas y, a la vez, nos habla de la complejidad de su situación contextual (en su casa no tiene luz, por ello debe participar de un piquete y, además, no puede usar su celular para el trabajo escolar). Según las palabras de su maestra, existe una situación barrial generalizada: "las familias no tienen wifi, no tienen conectividad. Por ejemplo, tengo un nene que vive en el barrio ' $\mathrm{X}$ ' que se tiene que subir al techo" (maestra de $7^{\circ}$ grado, escuela A, registro 22-05-2020).

Según la información relevada, es frecuente que haya un dispositivo móvil para todo el grupo familiar (en ocasiones, con varios/as niños/as en edad escolar que requieren del mismo), que funcione a tarjeta o con recargas, sobre todo los fines de semana que es cuando hay promociones; suelen ser aparatos que no cuentan con suficiente capacidad para descargar programas, archivos PDF, Word, o videos. Respecto al acompañamiento familiar en las tareas de las/os niños/as, observamos que las posibilidades de asistirlos/ as se encuentran condicionadas cuando los mismos padres y/o madres no han sido escolarizados/as. Dos docentes, una de primer grado de la escuela B y otra de séptimo de la escuela A, referencian tales dificultades en el repaso de las vocales y en la lectura de un libro de cuentos, respectivamente:

Las familias no pueden ayudarlos, muchas veces... vos das para la interpretación de un texto, yo les di un libro, les di Alicia en el país de las maravillas, que era el que estaba en la escuela, entonces vos por ahí es muy básico lo que vos podés preguntar, porque ellos están acostumbrados, son demandantes a que nosotros les expliquemos, nos sentemos al lado y ellos vayan llegando a ese camino, al proceso... Las familias muchas veces te mandan mensajes que no entienden, no entienden la consigna, no entienden la pregunta (maestra de $7^{0}$ grado, Escuela A, registro 22-05-2020). 
Les cuesta ayudarlos porque a veces hasta los mismos padres, si bien son consignas simples, no las comprenden... yo mandé una actividad, donde debían trabajar con las vocales, y la mamá me comenta si la podía ayudar porque ella se había olvidado de los temas de primer grado (maestra de $1^{\circ}$ grado, Escuela B, registro 22-05-2020).

Los registros precedentes revelan las complejidades que adquiere la docencia y el doble trabajo que realizan los/as maestros/as: por un lado, rediseñando las propuestas pedagógicas para adecuarlas a la modalidad de educación a distancia mediante la entrega de fotocopias semanales o quincenales; por otro lado - y en el afán de no "volver locos con las tareas a las familias"-, deben generar otras propuestas pedagógicas o, en palabras de una maestra, "hacerlo lo más sencillo y más simple posible para que esa mamá, a pesar de todos los problemas que tiene, también pueda ayudarle al hijo a hacer la tarea y que no sienta una frustración o que es un enojo" (maestra de $7^{\circ}$ grado, escuela A, R5-20, 22-05-2020). En otras palabras, relevamos que hay docentes que tratan de sostener la enseñanza en este contexto de no presencialidad -la llamada "continuidad pedagógica" - y que, al mismo tiempo, planifican los contenidos para que puedan ser trabajados y apropiados tanto por los/as niños/as como por quienes acompañan los procesos de enseñanza y que no constituyan una carga más para las familias.

\section{Reconfiguraciones del trabajo docente. "No soy amiga de la tecnología así que me tuve que amigar sí o sí"}

Que la pandemia haya irrumpido cuando el ciclo lectivo estaba iniciando implica que muchos/as docentes apenas conocían a sus alumnos/as. Aún en el caso de que continuasen con el mismo grupo-clase del año anterior, fueron pocas las jornadas escolares este año con motivo de feriados, períodos de adaptación de los/as más pequeños/as, paros y medidas de lucha docente. El desconocimiento de sus alumnos/as representa un obstáculo significativo a la hora de diseñar las actividades o realizar algún tipo de seguimiento:

A veces la respuesta es muy acotada porque he perdido contacto de los niños (...) si bien yo los conozco porque los tuve el año pasado (...) a veces [es difícil] sin tener contacto con el niño (maestra de $1^{\circ}$ grado, escuela B, registro 22-05-2020).

Soy maestra única de $4^{0}$ grado, de niños y niñas de lxs [sic] que prácticamente no les conozco sus trayectorias escolares (maestra de $4^{\circ}$ grado, escuela B, registro 26-05-2020).

Una de las primeras tareas que debieron realizar los/as maestros/as, luego de la suspensión de clases, fue recolectar la mayor cantidad de números de teléfono posibles (de planillas, padrones, formularios) lo cual, en algunos casos, llevó varias semanas lograr. Una de las estrategias iniciales desplegadas por las/os docentes fue la de armar grupos mediante la aplicación WhatsApp con las familias de sus alumnos/as.

Hice un grupo, el grupo no resultó porque nadie contestó. Entonces directamente empecé a mandarle audios en forma individual, que es lo que me sirve hoy. (maestra de nivel inicial, escuela $B$, registro 22-05-2020).

Si bien tengo un grupo de WhatsApp, en el grupo no están todas las familias, de hecho, no está ni la mitad, y quienes no están es porque no tienen celulares o no tienen internet. Y quienes sí están en los grupos, no tienen el celular como parte de su cotidianeidad o tienen un solo celular para toda la familia (maestra de $4^{\circ}$ grado, escuela B, registro 26-05-2020). 
Yo tengo un grupo con los padres en el cual de 28, 26-28 chicos que tengo en lista, son 4 con los que me comunico. Tengo algunos más, pero llegaré a 8,10, pero muchas veces no, no tengo respuesta de ellos (maestra de $1^{\circ}$ grado, escuela $B$, registro 22-05-2020).

Armamos grupos de WhatsApp, cada grado, de ahí mandamos tareas, pero (...) es muy complicado... entonces, no tienen las aplicaciones para descargar las tareas, no tienen conexión, por ahí tienen conexión los fines de semana (maestra de $7^{\circ}$ grado, escuela A, registro 22-05-2020).

Al no resultar el uso del celular un medio de comunicación eficaz, los/as docentes se volcaron al formato papel con el objetivo de llegar a todos/as sus estudiantes. Respecto a la elaboración de las propuestas pedagógicas, los/as maestros/as las suelen planificar entre pares, unificando criterios, para luego enviárselas a sus alumnos/as a través de las familias los días de reparto del bolsón de alimentos. La dirección de la escuela se convierte, de este modo, en una suerte de "copy express", según las palabras de una maestra (escuela A, registro 22-05-2020), debido a que la mayoría del plantel docente envía las actividades a la dirección para su impresión.

Acerca de las condiciones laborales de los/as docentes observamos que, si bien refieren contar en sus hogares con internet, computadora, celular e impresora, de manera generalizada, asumen ciertas limitaciones en el manejo de determinados soportes informáticos y/o digitales. Expresan desconocer ciertos programas y plataformas encontrándose, en ocasiones, siendo asistidos por sus propios/as hijos/as u otros familiares.

No soy hábil para lo cibernético, sería, y me tuve que ir amoldando a todo esto. No tanto con los chicos sino con los compañeros, las reuniones, el Jitsi, el zoom y todo eso... que no enganchaba una (maestra de $7^{\circ}$ grado, escuela $A$, registro 28-05-2020).

Sentarme con una computadora que no sé ni cómo se prende, un teléfono que, ya te digo, es viejo y bueno, tengo a mis hijos que me pueden ayudar a manejarlo (maestra de nivel inicial, escuela $B$, registro 22-05-2020).

Todo esto es muy nuevo, siempre he renegado de todo lo digital y bueno de repente ahora tengo que utilizar un montón de cosas, estar aprendiendo sobre la marcha y también hay cosas que no sé hacer... Eso me provoca un poco de fobia, tener que estar tanta cantidad de horas a veces sentada que con el celular, que con la compu, bajar distintos programas... que las videollamadas, que las reuniones plenarias (maestra de $1^{\circ}$ grado, escuela B, registro 22-05-2020).

Esta intensificación del trabajo docente se hace visible en las horas que permanecen frente a una pantalla, ya sea planificando las actividades, corrigiéndolas, contestando dudas o consultas. "Mi horario de trabajo es a cualquier hora", argumenta una docente (maestra de $1^{\circ}$ grado, escuela B, registro 22-05-2020), "es como que damos clase o nos hacen preguntas cualquier hora del día y cualquier día" (maestra de $7^{\circ}$ grado, escuela A, registro 22-05-2020). En ese sentido, un maestro refiere que son "muchísimas más" las horas que trabaja ya que, si bien ha establecido días y horarios para consultas y correcciones, se comunican con él a cualquier hora: "te escriben a la mañana, a la noche, a la madrugada. Bueno, a medida que vas pudiendo vas respondiendo, pero son las 24 horas prácticamente que estamos pendiente del teléfono" (maestro de $4^{\circ}$ grado, escuela B, registro 29-05-2020).

En líneas anteriores planteamos que el trabajo docente integra y, a la vez, traspasa el quehacer pedagógico, centrado en los procesos de enseñanza y aprendizaje, entramando elementos de diverso orden. Como venimos describiendo, tanto en la escuela A como en la $\mathrm{B}$ asisten docentes de forma voluntaria para colaborar con la entrega de bolsones 
de alimentos, ocasión de la que se valen para ponerse en contacto con las familias y entregar las propuestas para los/as niños/as. Ello habla de una mixtura de tareas que los/as docentes efectivamente ponen en acto. Planifican, secuencian y organizan los contenidos con el objetivo de convocar diariamente a los/as niños/as a trabajar (Rockwell y Caruso, 2020) y, simultáneamente, realizan otro tipo de actividades que no se hallan directamente vinculadas al trabajo con los conocimientos: recolección de información, visitas a las familias de los/as niños/as, tareas de alimentación, solicitudes burocráticas, reuniones. "Es otro laburo", plantea una docente de la escuela B en referencia al trabajo que realiza en su escuela, "más que mandarle y pegar papelitos o hacer el recorrido, es otro laburo (...) es todo el tiempo [saber] cómo están, que están haciendo" (maestra nivel inicial, escuela B, registro 22-05-2020). Si advierten que alguna familia no ha concurrido a la escuela a retirar el bolsón de alimentos, se organizan entre varios docentes y se lo acercan al hogar. En este sentido, una docente de la escuela A enuncia: "el trabajo que hacemos cuando vamos a la escuela es más social, por ejemplo, mañana yo voy a ir a la casa de un nene de una familia que esta familia no tiene... le cortaron la luz, tiene una hermana que está operada (...) Bueno, yo mañana voy a ver cómo está la familia" (maestra de $7^{\circ}$ grado, registro 28-05-2020). De diversos modos, los/as docentes intentan establecer contacto con las familias y así poder llegar a los/ as niños/as. El no vínculo con sus alumnos/as se señala como un potente obstáculo que tiende a fragmentar los procesos de enseñanza y aprendizaje. "Prácticamente no hay un ida y vuelta" (maestra de $4^{\circ}$ grado, escuela B, registro 26-05-2020); "lo fundamental es el vínculo, no hay otra, el vínculo. Y los que no tienen WhatsApp llamarlos (...) hay veces que tengo respuestas y a veces no" (maestra de nivel inicial, escuela $B$, registro 22-05-2020). ¿Cómo generar encuentros en este contexto? Una docente de primer grado menciona que, al problema de trabajar con niños/as que prácticamente no conoce o, en sus palabras, "casi trabajar desde el desconocimiento del niño, de su carita, de cómo es" (maestra de $1^{\circ}$ grado, escuela B, registro 22-05-2020), se suma la dificultad que supone la alfabetización a distancia:

(...) el no vinculo ¿no? en una parte tan importante como es la alfabetización inicial se hace como bastante complicado, uno debe trabajar con ellos en esta etapa, trabajar con material concreto, conocerlos y eso la verdad es que no está ocurriendo (maestra de $1^{\circ}$ grado, escuela B, registro 22-05-2020).

Se evidencia la emergencia de cierta preocupación docente por generar encuentros con los/as niños/as en la actual coyuntura de aislamiento y lograr algún tipo de interacción en este contexto de no presencialidad, "llegar a la mayor cantidad de chicas y de chicos posible" (maestro de $4^{\circ}$ grado, escuela B, registro 23-05-2020). Tal como lo relata una maestra: "mi cabeza funciona todo el tiempo pensando cómo puedo ayudar a tal o cual chico, cómo puedo llegar desde otro lugar" (maestra de $1^{\circ}$ grado, escuela B, registro 22-05-2020). Al mismo tiempo, advertimos una transformación en cuanto al cumplimiento de las tareas por parte de los/as niños/as y sus familias. "En un principio, había un poco más de participación, enviaban más las fotos de las actividades, pero después de algunas semanas, eso fue decayendo cada vez más" (maestra de $4^{\circ}$ grado, escuela B, registro 26-05-2020). Con el discurrir del tiempo, se fueron suscitando nuevas dificultades que se conjugaban con las ya existentes: no estar en contacto directo con los/as niños/as o, más aún, no conocerlos/as, el grado de participación que decae, proponer la misma actividad para todos/as.

No los ves, vemos a las familias cuando vamos a la escuela, pero a ellos no, no los vemos... Y después nosotras estamos acostumbradas a trabajar con cada uno de los chicos. Yo me siento (...) al lado de ellos y damos clase, atendemos a todas las necesidades, uno a uno (...) Entonces, dar la misma actividad para todos no es fácil (maestra de $7^{0}$ grado, escuela A, registro 22-05-2020). 
El trabajo respecto a los contenidos también deviene un eje sobre el que los/as docentes problematizan. ¿Qué contenidos priorizar? Si bien el Ministerio de la provincia de Santa Fe ha enviado cuadernillos a las escuelas con el objetivo de garantizar que todos los/as niños/as tengan acceso al material pedagógico, en ambas escuelas sucedió, de manera similar, que estos no representaron aportes relevantes. "Las actividades son ajenas", "no tienen en cuenta la realidad económica y social de las familias", "no están relacionadas con las planificaciones y proyectos propios", "los contenidos resultan elevados", son algunos de los motivos docentes aludidos. En la medida de las posibilidades, y sin soslayar las limitaciones existentes, los/as maestros/as intentan continuar con sus planificaciones. "Viene lerdo", describe una maestra ( $7^{\circ}$ grado, escuela A, registro 22-05-2020). "El cumplimiento es bastante, bastante [sic] escaso. De 60, son 7, 8 los que te responden todas las semanas con el tema de las actividades" (maestro de $4^{\circ}$ grado, escuela B, registro 23-05-2020). La dinámica que se presenta con mayor frecuencia es que los/as docentes entreguen las actividades a las familias entre los días lunes y martes, y que las consultas sobre ello lleguen varios días después, generalmente los sábados que es cuando suelen tener internet. Una docente relata: "hay dos que hacen todo perfecto, constante, la actividad diaria, así como lo vamos dando y hay otros que vienen semanas atrasados". A continuación, argumenta que dicha situación se debe principalmente a "un tema de desigualdad", tanto en las condiciones materiales como de conectividad de la mayoría de sus alumnos/as (maestra de $7^{\circ}$ grado, escuela A, registro 22-05-2020).

\section{Construyendo otras formas de enseñar en tiempos de distanciamiento obligatorio. Hacer pedagogía andando}

El análisis efectuado hasta aquí nos permite reafirmar la evidencia de que una clase no consiste en distribuir tareas (Dussen, 2020a; Dussel y Terigi, 2020), por el contrario, constituye un proceso de mayor complejidad que demanda la construcción insoslayable de vínculos, comunicación, diálogos e interacción. Enviar actividades descontextualizadas o para cumplir con disposiciones burocráticas no asegura per se que devengan en aprendizajes significativos, en todo caso, pueden derivar en una carga más para las familias. Para evitar que ocurra esto último, los/as maestros/as elaboran diversas estrategias, pedagogías de la emergencia (Dussel, 2020b), arman y desarman posibilidades e iniciativas combinando lo que tienen a mano. Como tendencia, observamos que los/as docentes desistieron de los grupos de WhatsApp los cuales, en algunos casos, terminaron funcionando para enviar información sobre los días de reparto del bolsón de alimentos o referida a las medidas de prevención e higiene sanitaria. La alternativa más productiva, dadas las dificultades para trabajar desde la virtualidad, fue la de elaborar actividades semanales (o quincenales) en diferentes archivos, imprimirlas y entregarlas a las familias cuando asisten a la escuela para la entrega del bolsón. Esto lo hemos relevado en ambas escuelas:

Cuando se le entrega el bolsón se le avisa que las tareas están en dirección para que retiren. Algunos envían a la vicedirección para que impriman, otros ya llevan las actividades hechas, impresas (maestro de $4^{\circ}$ grado, escuela B, registro 22-05-2020).

Nosotros mandamos la actividad a la escuela, entones desde la escuela la imprimen y se las dan en la mano (maestra de $7^{\circ}$ grado, escuela A, registro 22-05-2020).

La caracterización efectuada sobre los procesos de escolarización que se despliegan en estas escuelas, desde la no presencialidad, en ocasiones sin conocer a los/as niños/as, mediante contactos intermitentes, con familias en condiciones materiales y de conectividad desiguales, constituyen dimensiones sobre las cuales se interrogan los/as docentes. En palabras de una maestra: "ahí entra la contradicción y la pregunta de cuál es 
nuestro rol en la educación y en este contexto" (maestra de $4^{\circ}$ grado, escuela $\mathrm{B}$, registro 26-05-2020). ¿Cómo dar clase en estas condiciones? ¿Qué sentidos adquiere lo escolar y que lugares ocupa el/la docente en este tiempo? Se arman múltiples escenarios, los/ as docentes tejen caminos e iniciativas orientados a generar algún tipo de encuentro, de diálogo, de comunicación e intentar que los niños/as no desistan (Dussel, 2020a). "Mi mensaje es que ellos la hagan solos como puedan", relata un maestro ( $4^{\circ}$ grado, escuela B, registro 23-05-2020). En el camino de reinventar formas de estar, dicho docente elabora cuadernillos con tareas quincenales, estableciendo los días viernes para las correcciones y los martes para las consultas (más como una formalidad, ya que en la práctica las consultas llegan en cualquier horario). Lo que destacamos de su propuesta pedagógica es la invitación a sus estudiantes a que realicen las actividades solos, sin ayuda de los mayores ya que, posteriormente, él les enviará un audio con la explicación de los ejercicios y una imagen con los resultados para que puedan realizar la propia autocorrección e identificar si se equivocaron.

Y ahora lo que implementamos (...) es los martes cuando hacemos la entrega de los bolsones, que los padres me puedan dejar las actividades que hicieron los chicos y bueno, traérmelas acá y realizarles las correcciones porque ya de por sí a los chicos les gusta que le corrijan y bueno, ponerle alguna frase motivadora en las correcciones y que ellos puedan ver que uno está pendiente de lo que van haciendo también está bueno (maestro de $4^{\circ}$ grado, escuela B, registro 29-05-2020).

Diseñar las propuestas pedagógicas entre pares, con imágenes, colores e incluso con juegos, orientadas a que su realización no represente una carga ni para los/as niños/ as ni para sus familias. Situaciones semejantes observamos en la escuela A, donde una docente refiere que envían actividades "más artísticas o juegos u otra cosa como para que la vayan pasando bien (...) tampoco podemos picotear nosotros la cabeza con la tarea porque tenemos que cumplir al Ministerio de Educación" (maestra de $7^{\circ}$ grado, escuela A, registro 22-05-2020). Desafío constante, aún más difícil en este momento contextual, el de convocar a los/as niños/as al trabajo, de acompañarlos/as en los procesos de enseñanza, de generar lazos y que estos se sostengan en el tiempo luego de más de seis meses de suspensión de las clases presenciales.

\section{Palabras finales}

Volver a las aulas y a tener contacto con los niños es lo que más deseo (maestra de $1^{\circ}$ grado, escuela B, registro 22-05-2020).

El 20 de marzo del corriente año el Poder Ejecutivo Nacional estableció que las clases presenciales en la Argentina debían suspenderse como medida de prevención sanitaria. Sin preludios, las escuelas cerraron sus puertas. En aquellos contextos socioculturales con determinadas condiciones económicas, laborales, tecnológicas y de conectividad garantizadas, fue posible una "migración", un pasaje, de ciertas actividades escolares desde la presencialidad a la virtualidad, tal vez, con escasas dificultades. Plataformas web, Classroom, correo electrónico, WhatsApp, Zoom, una multiplicidad de soportes y canales que, potencialmente, abren caminos para que la enseñanza acontezca pero que, por sí solas, no garantizan que el proceso ocurra, requiriendo de la presencia de un/a docente que guíe y oriente dicho encuentro, de conectividad, de dispositivos tecnológicos, así como de determinadas condiciones materiales. Si, como hemos sostenido a lo largo de este artículo, hacer escuela implica una suspensión, aunque transitoria, del tiempo y del espacio ordinario, estamos en condiciones de afirmar que la pretensión de trasladar la "escuela al hogar" no puede efectuarse integralmente en la medida en que se trata de dos espacios diferenciales, cada uno con sus lógicas, tiempos y espacios 
(por supuesto, sin desconocer las múltiples interrelaciones que se producen entre las escuelas y las familias). Aun en aquellos contextos más favorecidos emerge una doble evidencia que no podemos eludir. Por un lado, que "hacer escuela en casa" ocasiona una superposición de espacios donde el hogar deviene multifunción y lo escolar se reduce a realización de tareas y, por otro, la constatación de que en el hogar faltan los/ as compañeros/as, los/as docentes, los recreos.

Retomando la anticipación hipotética formulada al inicio, planteamos una reconfiguración del trabajo docente en este tiempo de pandemia. Focalizando el análisis en los procesos desplegados en dos escuelas de la ciudad de Rosario, hemos descripto las condiciones contextuales de los/as niños/as y sus familias, las particularidades que adquiere la educación a distancia en tales espacios barriales atravesados por la desigualdad, allí donde no están garantizados los servicios básicos y la situación laboral para muchos/as es de incertidumbre. Para dar cuenta de determinados procesos que reconfiguran el trabajo docente hemos tomado en consideración diversos ejes analíticos como la relación docente-alumnos/as; la emergencia de nuevos (y reactualización de viejos) soportes y materialidades pedagógicas; las condiciones laborales; el trabajo con los contenidos. Detenernos en tales escenarios contextuales nos permitió poner en relación y comprender las estrategias desplegadas por las/os docentes, sus formas de actuación y los modos de establecer vínculos con sus alumnas/os. Encontramos prácticas como asistir de manera voluntaria a la escuela para la entrega del bolsón de alimentos, contactar telefónicamente a las familias para conocer su situación, visitar sus hogares para entregar las tareas o el bolsón a quienes no pudieron retirarlo, diseñar propuestas pedagógicas entre pares y adecuarlas a los contextos sociotécnicos de sus alumnos/as.

Sin lugar a dudas, la pandemia y posterior medida de aislamiento social, preventivo y obligatorio ha ocasionado reconfiguraciones de los procesos escolares caracterizados, en la actualidad, por la no presencialidad de los cuerpos, por una fragmentación de los lazos maestros/as-estudiantes, por la emergencia de nuevas materialidades y soportes pedagógicos. ¿Qué sentidos se construyen actualmente en relación a las escuelas? Fundamentalmente se hace evidente, en este tiempo de excepcionalidad, el carácter irremplazable de las escuelas (Southwell, 2020). Y al sostener ello, no nos referimos exclusivamente a los procesos de enseñanza y aprendizaje que allí se despliegan, sino a una valorización de las escuelas como espacios esenciales para la socialización tanto de los/as niños/as como de los/as maestros/as. Hacer escuela en casa es una pretensión que difícilmente pueda concretarse de modo integral pero que, tal vez, maniobre en favor de cierta continuidad pedagógica en este excepcional escenario escolar, hasta que las clases regresen a la presencialidad. 


\section{Q Bibliografía}

》Achilli, E. (1986). La práctica docente: una interpretación desde los saberes del maestro. Cuadernos de Formación Docente. Universidad Nacional de Rosario.

»Achilli, E. (1996). Práctica docente y diversidad sociocultural. Rosario, Homo Sapiens.

" Achilli, E. (2005). Investigar en Antropología Social: los desafíos de transmitir un oficio. Rosario, Laborde.

"Achilli, E.; Pavesio, M. V. y Vera, R. (2019). Trabajo docente en contextos de pobreza urbana. Una aproximación comparativa de las últimas décadas. En Tálamo, F. et al. Política educativa, sindicalismo y trabajo docente: hacia la resignificación de los debates políticos y académicos en torno a las prácticas pedagógicas y sindicales para

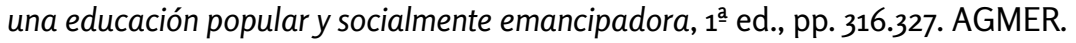

» Batallán, G. (1983). Talleres de Educadores. Capacitación mediante la investigación de la Práctica. Buenos Aires, FLACSO.

»Dussel, I. (2020a). La clase en pantuflas. Conversatorio virtual en el marco del espacio Diálogos sobre pedagogía, desde el Instituto Superior de Estudios Pedagógicos. 23 abril. Disponible en https://www.youtube.com/watch?v=6xKvCtBC 3 Vs

»Dussel, I. (2020b). La formación docente hoy: entre atender la emergencia y pensar nuevos horizontes. Videoconferencia. Programa de Formación Docente a distancia. Disponible en: https://www.youtube.com/watch?time_continue=1725\&v=UIPfz/9qL oo\&feature $=$ emb_logo

»Dussel, I. y Terigi, F. (2020). El desafío político de continuar enseñando con sentido inclusivo. Las prácticas en contextos de distanciamiento. "Jornadas Nacionales de Formación Docente: El sentido de educar: reflexiones sobre vínculos y continuidad pedagógica". Organizadas por el Instituto Nacional de Formación Docente (INFoD). 21 de mayo. Disponible en https://www.youtube.com/watch?v=pZYGWiznHQM

" Masschelein, J. y Simons, M. (2014). Defensa de la escuela. Una cuestión pública. Buenos Aires, Miño y Dávila.

» Rockwell, E. (2013). El trabajo docente hoy: nuevas huellas, bardas y veredas. XI Congreso Nacional de Investigación Educativa. Conferencias Magistrales. México, Consejo Mexicano de Investigación Educativa.

» Rockwell, E. y Caruso, M. (2020). ¿Reinventar la escuela? ¡Reivindicar la escuela! Reflexiones desde una perspectiva histórica. Panel de apertura en "Jornadas Nacionales de Formación Docente: El sentido de educar: reflexiones sobre vínculos y continuidad pedagógica". Organizado por el Instituto Nacional de Formación Docente (INFoD). 21 de mayo. Disponible en https://www.youtube.com/ watch?v=OULlew9BGKg

»Southwell, M. y Batthjany, K. (2020). Miradas latinoamericanas a la educación en tiempos de pandemia. Ciclo Internacional de conversatorios: Educación y Humanidad en tiempos de pandemia, perspectivas multisituadas, organizado por CLACSO, la Universidad de Antioquia y la Universidad Nacional de la Plata. Disponible en: https://www.youtube.com/watch?v=S_Kc9RYghyg\&t=6s

» Terigi, F. (2020). El desafío político de continuar enseñando con sentido inclusivo. Las prácticas en contextos de distanciamiento. Mesa Panel en "Jornadas Nacionales de Formación Docente: El sentido de educar: reflexiones sobre vínculos y continuidad pedagógica". Organizado por el Instituto Nacional de Formación Docente (INFoD). 
21 de mayo. Disponible en https://www.youtube.com/watch?v=pZYGWiznHQM

"Vera, R. (1988). Orientaciones básicas de los Talleres de educadores. Cuadernos de Formación Docente. Universidad Nacional de Rosario.

\section{María Victoria Pavesio}

Profesora y Licenciada en Ciencias Antropológicas, Universidad Nacional de Rosario. Becaria doctoral, Consejo Nacional de Innovación, Ciencia y Tecnología, Facultad de Filosofía y Letras, Universidad de Buenos Aires (área Antropología). Integrante del Centro de Estudios Antropológicos en Contextos Urbanos (CeaCu), Facultad de Humanidades y Artes, Universidad Nacional de Rosario. vickypavesio@hotmail.com 
